\title{
The Effect of Calcium Nutrition on the Production of Diffusible Antigens by Rhizobium trifolii
}

\author{
BY BEVERLEY A. HUMPHREY AND J. M. VINCENT \\ Microbiology Laboratory, School of Agriculture, University of Sydney, \\ Australia
}

(Received 9 April 1965)

\begin{abstract}
SUMMARY
Rhizobium trifolii grown in a defined medium deficient in calcium yielded additional diffusible antigens as compared with organisms receiving calcium or strontium. The two kinds of organisms were indistinguishable in respect of their somatic agglutinogens. The same additional precipitinogens were released from Ca-adequate bacteria by mechanical disintegration, freezing, drying, lysozyme or chloroform. Their occurrence in the untreated Ca-deficient bacteria is attributed to autolysis of these more fragile bacteria. The precipitinogen (' $a$ ' band) that was common to the $\mathrm{Ca}$-adequate and Ca-deficient bacteria was not shared by a second strain of $\boldsymbol{R}$. trifolii nor by 2 strains of $\boldsymbol{R}$. meliloti. This ' $a$ ' antigen was heat stable and appeared to be a component of the cell wall, from which it could be separated in diffusible form by formamide extraction of whole bacteria, trypsin digestion of broken bacteria and by mechanical disintegration of prepared cell walls. Neither of the additional antigens (' $b$ ', ' $c$ ') was related to agglutination; both were found in Ca-deficient or mechanically broken bacteria of the other strain of $R$. trifolii; ' $c$ ' only was similarly shared with $R$. meliloti. The ' $b$ ' band antigen appeared to be an intracellular component and was heat labile. Like ' $a$ ', 'c' was heat stable and associated with cell wall, but evidently was not ordinarily exposed, although readily released by lysis or mechanical breakage. The extracellular polysaccharide was neither antigenic nor haptenic, but the preparation obtained from Ca-deficient and mechanically broken Ca-adequate organisms was persistently associated with a co-precipitating antigenic component (chiefly ' $a$ ' band).
\end{abstract}

\section{INTRODUCTION}

Previous studies of a strain of Rhizobium trifolii (Vincent \& Colburn, 1961; Humphrey \& Vincent, 1962) showed that calcium deficiency produced morphological abnormality, and that the swollen spherical shape of the Ca-deficient bacteria could be attributed to shortage of $\mathrm{Ca}$ in the cell walls, with consequent weakening of structure. There appeared, however, to be no other readily detected change in the gross chemical structure of the cell walls. It seemed worth while, therefore, to use serological analysis to examine whether there are detectable differences in the organization of cell wall components. The work to be described was based partly on the agglutination of whole bacteria, but also used gel-diffusion methods. The latter have recently been applied to Rhizobium by Dudman (1964); Dr Dudman generously supplied us with details of his experience in advance of publication. 


\section{METHODS}

Organism and cultural conditions. Rhizobium trifolii strain su 297/31 was grown in a defined liquid medium (Vincent, 1962) having $\mathrm{mm}$ total divalent cation, made up of either $0.5 \mathrm{~mm}-\mathrm{Ca}^{2+}+0.5 \mathrm{~mm}-\mathrm{Mg}^{2+}$ (Ca-adequate) or $\mathrm{mm}-\mathrm{Mg}^{2+}$ (Ca-deficient). Cultures were shaken and incubated at $25^{\circ}$ and harvested after $72 \mathrm{hr}$ (early stationary phase).

Preparation of antisera. Antisera were prepared by a method similar to that of Dudman (1964) except that whole bacteria in a $72 \mathrm{hr}$ liquid culture were used throughout. The rabbits were injected first intramuscularly with $2 \mathrm{ml}$. of an emulsion containing equal volumes of Freund's complete adjuvant (Difco) and the bacterial culture. This culture thus included a considerable amount of extracellular polysaccharide (Humphrey \& Vincent, 1959) as well as any other soluble substances arising from metabolism or autolysis. One month later, $2 \mathrm{ml}$. of the same culture, which had been stored deep frozen, were injected intravenously without adjuvant. The animals were bled after one more week, by which time the agglutination titre, against the dialysis residue organisms of whole culture, was greater than 1600 . Two animals were used for each form of culture, Ca-adequate and Ca-deficient.

Agglutination and absorption by intact organisms. Intact-organism suspensions, either in saline $(0.85 \%, \mathrm{w} / \mathrm{v}, \mathrm{NaCl})$ after centrifuging down from whole culture, or the dialysis residue organisms from whole cultures, were used for somatic agglutination and antibody absorption by the usual methods (e.g. Vincent, 1941); three successive absorption cycles were required to remove all agglutinins (negative at $1 / 50$ ).

Gel diffusion. The Petri plate method of double diffusion (Dudman, 1964) was used. Oxoid Ionagar no. $2(0.75 \%, w / v$, in $0.85 \% \mathrm{NaCl}+0.25 \%$ sodium azide added when the plates were poured) was used to give a $4 \mathrm{~mm}$. depth of layer. Plastic Petri dishes were preferred since they had a flatter and more uniform base than had glass ones. Wells cut in the agar were $4 \mathrm{~mm}$. in diameter and were usually spaced $8 \mathrm{~mm}$. apart. Antisera were used undiluted. Bacteria centrifuged down from whole cultures at $27,000 \mathrm{~g}$ were resuspended in $0.85 \% \mathrm{NaCl}$ at a concentration equiv. $150 \mathrm{mg}$. dry wt. organism/ml. Maximum development of the precipitation lines was seen after incubation at $25^{\circ}$ in a moist atmosphere for 3-6 days.

Direct absorption of antibody or antigen could be demonstrated by mixing both reactants in a well in the agar. A suspension of bacteria containing equiv. 10-20 $\mathrm{mg}$. dry wt. bacteria $/ \mathrm{ml}$. saline was able to absorb precipitins from antiserum at a $1: 1$ by vol. ratio of reactants. Non-absorption, or excess of antibody or antigen, was then shown by formation of precipitation lines between the absorption well and a well containing antigen or antibody, as appropriate.

Cell walls. These were prepared as previously (Humphrey \& Vincent, 1962), but with omission of lyophilization of the bacteria before extracting the $\beta$-hydroxybutyrate polymer with chloroform. The sequence used in the present work, starting with the debris obtained by breaking the bacteria in a Mickle disintegrator with ballotini was: (i) to extract by shaking on a wrist-action shaker for $2 \mathrm{hr}$ with an equal volume of chloroform and then to remove the chloroform by centrifuging it to a clear bottom layer; (ii) to digest the wall material with trypsin; (iii) finally to wash the walls with $\mathrm{M}-\mathrm{NaCl}$ and then water, and to separate any whole bacteria by differential centrifugation. 
Ultraviolet (u.v.) absorption spectra. These were made on a Unicam SP 700 automatic recording spectrophotometer (Cambridge Instrument Co., Cambridge, England). The extinction at $260 \mathrm{~m} \mu\left(E_{260}\right)$ was taken as an index of the leakage of cytoplasmic components from the bacteria.

\section{RESULTS}

\section{Agglutination reactions with intact Rhizobium trifolii organisms}

There was no distinction between Ca-adequate and Ca-deficient Rhizobium trifolii, either by somatic agglutination or by cross-absorption. It was concluded therefore that both kinds of organism had the same agglutinogens, namely, antigens at or near the surface which involved the whole organisms in their reaction with antibody.

\section{Gel-diffusion precipitin tests with whole Rhizobium trifolii organism}

Homologous reactions. These are shown as the upper patterns of Fig. 1. Caadequate Rhizobium trifolii (positions $\mathrm{i}$ and iv) slowly formed a band of two precipitation lines near the antigen well when tested against the homologous antisera.

(i)

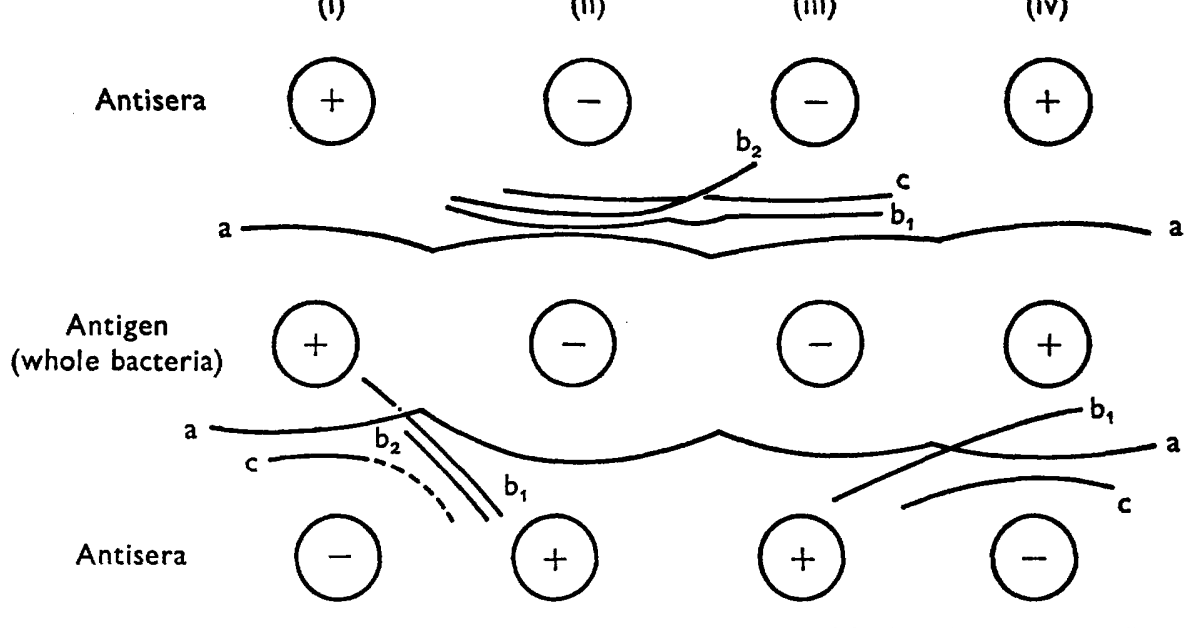

Fig. 1. Schematic representation of gel-diffusion patterns with Ca-adequate and Cadeficient organisms of Rhizobium trifolii. Centre row of wells with suspensions of whole organisms of $\boldsymbol{R}$. trifolii (Ca-adequate, +; Ca-deficient, - ). Top row of duplicate antisera arranged to give homologous patterns; bottom row, heterologous and test of unique antigens. $\times \mathbf{2}$.

These lines, lying close together and slightly curved with the concave side towards the antigen well, will be referred to as the ' $a$ ' band. Ca-deficient organisms (positions ii and iii) reacted differently with their homologous antisera in that they developed, in addition to the ' $a$ ' band, at least two fast-moving and quickly developing bands nearer the antiserum well, and concave towards it. These will be designated ' $b$ ' and ' $c$ ' (see Fig. 1). The ' $b$ ' band was made up of one (' $b_{1}$ ', position iii) or two (' $b_{1}$ ', ' $b_{2}$ ', position ii) thin sharp lines, and was the first to appear. The diagonal between the Ca-deficient organisms (position iii) against antiserum to 
Ca-deficient organisms (position ii) resulted from the additional ' $b$ ' line (' $b_{2}$ ') antibody in the latter. The ' $c$ ' band constituted a weaker line nearest the antiserum well and was not further resolved. Both ' $b$ ' and ' $c$ ' bands disappeared when the antiserum was diluted more than twofold, but the ' $a$ ' band was still seen at a 32-fold dilution.

Heterologous and cross reactions for unique antigens. Antisera to Ca-adequate organisms produced only the ' $a$ ' band with Ca-deficient organisms (Fig. 1, lower positions ii, iii), but the reciprocal heterologous reaction sometimes showed the ' $c$ ' band as well (e.g. lower patterns i, iv). The crossing lines formed between antisera to Ca-deficient organisms and the diagonally opposite Ca-deficient organisms (i/ii; iv/iii) showed the ' $b$ ' band unique to this situation. In agreement with the difference in the two 'Ca-deficient' antisera as revealed with the homologous reaction, i/ii gave two lines (' $b_{1}$ ', ' $b_{2}$ ') whereas iv/iii gave only ' $b_{1}$ '.

The detailed difference between the two antisera to Ca-deficient organisms in respect of the ' $b$ ' band antibodies is of the kind likely to be encountered between different animals receiving the same course of injections (Crowle, 1960).

The occurrence of a weak ' $c$ ' band in the reaction between about half the batches of Ca-adequate organisms and antisera to Ca-deficient bacteria needs to be considered in the light of further observations (below) that the ' $c$ ' antigen diffused slowly from isolated cell walls. It seemed that some batches of $\mathrm{Ca}$-adequate organisms liberated more of this near-surface antigen than others. The absence of the corresponding antibody in the antisera to $\mathrm{Ca}$-adequate organisms indicates that either the particular immunizing suspensions were relatively intact, or that the substance released from some of the Ca-adequate organisms was an incomplete antigen (complex hapten). The absence of any ' $b$ ' band between Ca-adequate bacteria and the antisera to Ca-deficient cells showed that autolysis as such was not involved. Rhizobium trifolii grown on an entirely different medium (yeast-extract mannitol agar) exhibited the same gel-diffusion pattern against these antisera as did those organisms grown on a defined $\mathrm{Ca}$-adequate medium. Organisms grown with strontium instead of calcium, and which therefore showed normal morphology (Vincent \& Humphrey, 1963), gave a 'Ca-adequate' diffusion pattern.

Absorption directly in the well showed the identity of the antigens responsible for the ' $a$ ' bands of both Ca-adequate and Ca-deficient organisms. Ca-deficient bacteria (with ' $a$ ', ' $b$ ' and ' $c$ ') were able to absorb completely the antisera to Caadequate organisms (anti-' $\mathrm{a}^{\prime}$ ). On the other hand Ca-adequate organisms absorbed anti-' $a$ ' and anti-'c', but not anti-' $b$ ', from 'Ca-deficient' antisera.

\section{Fragility of Ca-deficient Rhizobium trifolii}

Ca-deficient Rhizobium trifolii organisms appeared to be more fragile than the normal bacteria in that about $50 \%$ more $E_{260}$-absorbing compounds accumulated in the culture fluid and twice as much was released when the harvested bacteria were suspended overnight in distilled water or saline, or were frozen and thawed in distilled water. This was confirmed by the greater mass of debris seen in electron micrographs of suspension of Ca-deficient organisms as compared with that in suspensions of $\mathrm{Ca}$-adequate bacteria. 


\section{Extracellular antigens}

A crude polysaccharide-containing fraction was prepared from culture fluids (bacteria removed at $27,000 \mathrm{~g}$ ), by evaporation to small bulk in a rotary vacuum distillation apparatus at $40^{\circ}$, dialysis to remove salts and mannitol and the dialysis residue evaporated to dryness at $40^{\circ}$ or freeze-dried. The end-product, dissolved in saline, was used for gel diffusion. This method is similar to that described by Dudman (1964) to prepare his extracellular antigens. Such a fraction from Caadequate cultures showed the ' $a$ ' band only, whereas the ' $a$ ', ' $b$ ' and ' $c$ ' bands appeared in the extracellular antigens from Ca-deficient cultures. Like Dudman, we found that all precipitation lines in the extracellular preparations were readily shown with suspensions of washed whole bacteria containing the same weight of dry substance/ml.

More highly purified polysaccharide fractions were prepared by precipitation from the supernatant fluids of centrifuged cultures, either by adding cetyltrimethylammonium bromide or ethanol, followed by reprecipitation with ethanol and deproteinization by the Sevag method (Sevag, Lackman \& Smollens, 1935). The polysaccharide fraction prepared in any of these ways from Ca-adequate cultures gave no gel-diffusion lines. On the other hand, polysaccharide from Ca-deficient cultures, even when precipitated twice from ethanol and deproteinized, showed the ' $a$ ' band and occasionally faint ' $b$ ' and ' $c$ ' bands. The possibility that Ca, bonded with the polysaccharide fraction of Ca-adequate bacteria, might thereby restrict the diffusion or functioning of constituent antigens was not supported by the fact that the addition of EDTA to the polysaccharide solution did not produce any precipitation bands. Moreover, polysaccharide prepared from a mechanically disintegrated whole culture of Ca-adequate bacteria showed a definite ' $a$ ' band even after repeated precipitation and deproteinization.

If the polysaccharide were to represent a partial antigen unable to precipitate with antibody after separation from a larger or cell-bound component, it might still be expected to inhibit reactions involving the whole antigen. To test this, antisera against $\mathrm{Ca}$-deficient and Ca-adequate bacteria were mixed in the agar wells with an equal volume of concentrated polysaccharide solution, and tested against $\mathrm{Ca}$-adequate and $\mathrm{Ca}$-deficient bacteria. In no case did the polysaccharide from $\mathrm{Ca}$ adequate bacteria inhibit the reaction between antisera and bacteria, suggesting that the lack of precipitation bands from this preparation did indeed indicate lack of antigenic activity. As expected, the polysaccharide fraction from Ca-deficient bacteria known to contain the ' $a$ ' antigen absorbed the corresponding ' $a$ ' antibody from both antisera, whilst leaving the ' $b$ ' and ' $c$ ' antibodies of 'Ca-deficient' antisera free to react. These results lend no support to any suggestion that the extracellular polysaccharide itself is even haptenic.

\section{Gel diffusion with disintegrated Rhizobium trifolii organisms}

Ca-adequate Rhizobium trifolii organisms which had been shaken with ballotini in a Mickle disintegrator were practically all broken in 5 min., as indicated by the stained appearance, viable counts, and the u.v.-absorption of the supernatant fluid. This broken unfractionated material showed all of the gel-precipitation bands of unbroken Ca-deficient organisms. When broken organisms were centrifuged at 
$27,000 \mathrm{~g}$, the debris, consisting of cell walls, $\beta$-hydroxybutyrate polymer (Humphrey $\&$ Vincent, 1962) and a few unbroken bacteria, showed the ' $a$ ' and ' $c$ ' lines. The supernatant fluid (cell contents and finest debris), when concentrated by lyophilization and resuspended in saline, produced a strong ' $b$ ' line, in addition to lines ' $a$ ' and ' $c$ '. Continuation of disintegration for $120 \mathrm{~min}$. did not further change the geldiffusion pattern. It was also found that Ca-adequate organisms liberated some of the ' $b$ ' and ' $c$ ' antigens when frozen, and particularly when freeze-dried. Curiously these antigens were the first to disappear from very old (22-40 day) Ca-deficient cultures.

Heat stability of precipitinogens. A suspension of disintegrated bacteria containing antigens of all three bands was heated in sealed ampoules at $96^{\circ}$. The antigens of the ' $a$ ' and ' $c$ ' bands were stable for the full period of $2 \mathrm{hr}$; ' $b$ ' disappeared within $30 \mathrm{~min}$.

Chloroform-extracted residue. The residue of the debris from breaking with the Mickle disintegrator showed mainly the ' $a$ ' band after chloroform extraction. The extract itself after evaporation to dryness yielded a thin plastic film which, when taken up with saline, gave faint ' $a$ ', ' $b$ ' and ' $c$ ' bands, probably due to some bacteria and cell walls caught up in the sticky mass.

Chloroform extraction of whole bacteria, under conditions similar to those used for extracting the debris, did not decrease their agglutinability. Gel diffusion with the same extracted bacteria now showed the pattern typical of 'Ca-deficient' and mechanically disrupted bacteria.

Trypsin digestion. The residue after disintegration and extraction with chloroform was treated with trypsin to remove adhering cytoplasm, and centrifuged at $27,000 \mathrm{~g}$. The supernatant fluid, dialysed, lyophilized and resuspended in saline, showed the ' $a$ ' band. Concentrated washings from the debris, first with $\mathrm{M}-\mathrm{NaCl}$ and then repeatedly with water, showed traces of all three bands, particularly the ' a' band.

Antigenic properties of cell walls. The bacterial residues retained their agglutinability through all stages, up to and including the cell-wall preparation itself. In all cases the titre remained high $(>800)$, but the nature of the agglutination changed from the fine granular deposit, characteristic of the whole bacteria and unextracted broken bacteria, to an abundant loose flocculent precipitate in the cases of the trypsin-digested residue and the final cell-wall preparation. In gel diffusion, the ' $a$ ' band antigens were associated with the residue up to the stage of trypsin digestion; they were then readily shown in the supernatant fluid but not in the residue and final cell-wall preparation, both of which were still agglutinable. Long diffusion with most cell-wall preparations, shown under the electron microscope to be relatively clean, still gave a faint ' $c$ ' line, and occasionally a close almost nondiffusing area of precipitation around the antigen well. When the cell walls of such preparations and cell walls which showed no diffusion pattern at all were suspended in saline and treated in the Mickle disintegrator for $1 \mathrm{hr}$, the diffusion pattern then showed definite ' $a$ ' and ' $c$ ' lines. With the appropriate parallel arrangement of wells, it was found that the ' $a$ ' band which developed from disintegrated cell walls curved in to join up with the closer 'non-diffusing' area of precipitation seen around the wells which contained intact cell walls.

Rhizobium trifolii was grown in a medium relatively deficient in mannitol $(0.2 \%$, 
$\mathrm{w} / \mathrm{v}$, as compared with $1 \%, \mathrm{w} / \mathrm{v})$ so as to accumulate less polymer (10-12 \% of dry wt. bacteria as compared with 40-50\%) and permit the preparation of cell walls without chloroform extraction, since this might destroy a lipopolysaccharide layer in the walls. However, no difference was detected in agglutinability or diffusion pattern between cell walls prepared in this way and those which had had the usual treatment with chloroform.

\section{Other methods of breakdown and extraction}

Lysozyme. Lysozyme even without EDTA, liberated the ' $b$ ' and ' $c$ ' antigens from Ca-adequate bacteria. This might mean that the small degree of lysis found under these conditions (17\% as compared with $61 \%$ with EDTA; Vincent \& Humphrey, 1963) was enough to liberate a reacting concentration of intracellular antigen.

Formamide extractions. The conditions were those of Bjorklund (1953), with lyophilized Ca-adequate whole bacteria in 25 parts by wt. formamide at $5^{\circ}$ for $\mathbf{3 0}$ min. shaken in a Mickle disintegrator without ballotini. The extract gave a heavy flocculent precipitate on adding 2 vol. acetone; on resolution and diffusion this material produced a heavy double ' $a$ ' band. The extracted bacteria showed a new complexity of diffusible antigens. In particular, the ' $a$ ' antigens diffusing from extracted bacteria gave a pattern of three lines.

\section{Intra- and interspecific cross-reactions}

Cross-reactions between Rhizobium trifolii strain su 297/31 and $\boldsymbol{R}$. trifolii strain TA 1 were studied by agglutination and gel diffusion. Somatic cross-agglutination was negative at $1 / 50$ dilution of antiserum but some cross-precipitation was observed with mechanically broken organisms. Antigens responsible for ' $b$ ' and ' $c$ ' lines appeared to be common to both strains, but the ' $a$ ' band was found only with each homologous antiserum. When disintegrated bacteria of two strains of $R$. meliloti (su 47, $U$ 4.5) were tested by gel diffusion against the antisera against both strains of $\boldsymbol{R}$. trifolii, a faint but definite line was observed in the ' $c$ ' position near the antiserum well.

\section{DISCUSSION}

Whereas the agglutination reaction, as ordinarily observed, depends on a firm structural relationship between an exposed antigen (agglutinogen) and the bacterium, precipitation reactions are able to reveal only soluble antigen (precipitinogen). Gel diffusion is likely not to detect agglutinogens (except so far as these might become detached, probably as incomplete antigens), and is less readily interpreted in spatial terms in that it need not be restricted to surface antigens. In this connexion, the structural integrity of the bacteria used for the preparation of antisera and in testing is obviously of paramount importance. Various means of disintegration can be used to reveal additional diffusible antigens (mechanical, sonic, chemical, enzymic) and the results can be interpreted accordingly. However, care must be used to avoid uncontrolled autolysis (Lennox, 1960). The age of a culture, its aeration and the nature of the culture medium are factors which must be controlled and their effects examined.

In the present work, the Ca-adequate Rhizobium trifolii organisms, well aerated 
and harvested early in the stationary phase appeared to be relatively unautolysed. The ' $a$ ' band, shown in the gel-diffusion test, can therefore be regarded as due to soluble precipitinogen(s) located at or near the surface. The consistent difference between antisera against the $\mathrm{Ca}$-adequate and $\mathrm{Ca}$-deficient bacteria is reassuring, in that it shows that there was little, if any, liberation of deep-seated antigens in the animal being immunized.

The ' $b$ ' and ' $c$ ' antigens regularly revealed in Ca-deficient bacteria, and also liberated from mechanically broken Ca-adequate bacteria, do not represent new antigens in the strict sense. Rather they are an expression of leakage from the more fragile Ca-deficient bacteria of internally located antigenically competent macromolecules. The work of Niwa, Yamadeya \& Kuwajima (1964), with Bordetella (also Gram-negative), is significant in this connexion. These workers found that leakage of RNA was increased by a variety of agents which might be expected to remove Ca from the cell walls (including oxalic acid, EDTA, phosphoric and arsenic acids); on the other hand $\mathrm{Ca}$, but not $\mathrm{Ba}$, decreased the leakage. No details were given, however, concerning the initial Ca status of the organisms. Although the lipoprotein-lipopolysaccharide outer layer of the wall of Gram-negative bacteria is considered to be the dominant antigenic surface, most parts of the cell have been found, in various organisms, to be antigenic. Antigenicity has been observed in the cytoplasmic membrane of Bacillus megaterium (Vennes \& Gerhardt, 1956), which contains lipoprotein and some RNA; in a protein and nucleic acid-polysaccharide complex from Rhizobium (Lorkiewicz, Kwas \& Szwed-Nabialek, 1963); and in intracellular enzymes of Neurospora (Roberts \& Pateman, 1964). That deep-seated antigens should be shared between varieties of Rhizobium trifolii and between Rhizobium species is not perhaps unexpected; compare, for example, intracellular group-specific glycerol teichoic acids of Lactobacillus species (Sharpe, Davison \& Baddiley, 1964), and the intracellular protein that constitutes the group D specific antigen of Streptococcus (Jones \& Shattock, 1960).

The qualitative identity of the Ca-adequate and Ca-deficient Rhizobium trifolii organisms in the cross-absorption agglutination test shows that the additional precipitinogens shown with Ca-deficient organisms were unrelated to agglutinogens. Reciprocally this was confirmed by the fact that ' $b$ ' and ' $c$ '-band antigens were shared between the two strains of $R$. trifolii and the 'c' band with $R$. meliloti, in both cases without cross-agglutination. There might, however, be some relationship in the case of the ' $a$ ' band precipitinogens in that: (i) they were common to the cross-agglutinating $\mathrm{Ca}$-adequate and Ca-deficient organisms; (ii) they were not shared with the non-cross-agglutinating strain and species; (iii) like the somatic agglutinogens, they were heat stable; (iv) they occurred at the surface and were closely associated with the cell wall. It seems sound to conclude that the 'a'-band antigens are part of the cell-wall structure which may, when thus anchored on the organisms, be responsible for agglutination. The fact that the ' $a$ '-band disappeared from the gel-diffusion pattern of the residue after trypsin digestion but appeared in the supernatant fluid, indicates the release of an antigenic complex by the breakage of peptide links. The fact that formamide extracted the ' $a$ ' antigen from Rhizobium organisms may further indicate its lipopolysaccharide nature. The ' $a$ ' antigen may be a complex of related or unrelated chemical entities; indeed the band we observed was made of at least two closely associated lines. The fact that relatively violent 
reagents (e.g. phenol, Davies, 1956; formamide, Krause \& McCarty, 1961) have been used to isolate specific antigenic substances from bacterial walls makes it likely that the walls would retain non-diffusible antigens in spite of the rigours of cell-wall preparation, and that these might be available for agglutination but not immediately for diffusion. In our case, mechanical disintegration released a diffusible fraction which reacted in the ' $a$ ' band. The greater diffusibility of these disintegrated walls seems likely to reflect the release of antigenic components in a smaller and more mobile form. The antigen of the ' $c$ ' band, although evidently playing no role in agglutination, appeared to be relatively superficial, as judged by the ease with which it was liberated from Ca-adequate organisms and from isolated walls. Its heat stability as compared with heat-labile ' $b$ '-band antigens might reflect association with the wall rather than with cytoplasm.

Our present work, like earlier results (Kleczkowski \& Kleczkowski, 1952; Humphrey \& Vincent, 1959) indicates that extracellular polysaccharide of Ca-adequate Rhizobium trifolii is neither antigenic nor haptenic (except so far as it may react with antibody already developed against polysaccharide of type III Pneumococcus; Schluchterer \& Stacey, 1945). The persistent diffusible antigens of 'purified' polysaccharide of Ca-deficient Rhizobium trifolii organisms seem to represent a coprecipitating fragment released from the fragile organism. This conclusion is supported by the fact that a similar persistent antigen occurred in polysaccharide from mechanically disrupted Ca-adequate organisms. Our experience, like that of Dudman (1964) with $\boldsymbol{R}$. meliloti, in which diffusing antigens were better demonstrated in washed whole organisms than in concentrated extracellular preparations, supports the idea that such reactions as have been observed with the water-soluble polysaccharides of rhizobia were due to contaminating cellular components. The extracellular polysaccharide appears to be a diffuse exudate without a morphological role. Glucuronic acid, known to be a major component of the extracellular polysaccharide could not be detected in the cell walls of $\boldsymbol{R}$. trifolii (Humphrey \& Vincent, 1962). Pappagianis, Putman \& Kobayashi (1961) attributed to somatic contamination some antigens which occur in polysaccharide preparations from culture filtrates of Coccidioides immitis. The same considerations would contraindicate the preparation of polysaccharides by cetyltrimethylammonium bromide precipitation from whole cultures in view of this agent's known lytic action (Salton, 1957).

Our thanks are due to Dr D. G. Drummond and Mr R. G. Wright of the Electron Microscope Unit, Sydney University; and to Dr G. F. Humphrey of the C.S.I.R.O. Division of Fisheries and Oceanography for the ultraviolet spectra. The work reported in this paper was supported by the Reserve Bank of Australia (Rural Credits Division), the Wheat Industry Research Funds and the Research Committee, University of Sydney.

\section{REFERENCES}

BJorkuUnd, B. (1953). Immunological studies of rabbit bone marrow with the aid of gel diffusion and serological techniques. Internat. Arch. Allergy, 4, 379.

Crowle, A. J. (1960). Interpretation of immunodiffusion tests. Ann. Rev. Microbiol. 14, 161. 
Davies, D. A. L. (1956). A specific polysaccharide of Pasteurella pestis. Biochem. J. 63, 105.

Dudman, W. F. (1964). Immune diffusion analysis of the extracellular soluble antigens of two strains of Rhizobium meliloti. J. Bact. 88, 782.

Humphrey, B. A. \& Vincent, J. M. (1959). Extracellular polysaccharides of Rhizobium. J. gen. Microbiol. 21, 477.

Humphrey, B. A. \& Vincent, J. M. (1962). Calcium in cell walls of Rhizobium trifolii. J. gen. Microbiol. 29, 557.

Jones, D. \& Shatrock, P. M. F. (1960). The location of the group antigen of group D Streptococcus. J. gen. Microbiol. 23, 335.

KLeczkowski, J. \& KLeczkowski, A. (1952). The effect of specific polysaccharide from the host bacteria and of ribonuclease on the multiplication of Rhizobium phages. J. gen. Microbiol. 7, 340.

Krause, R. M. \& McCarty, M. (1961). Studies on the chemical structure of the streptococcal cell wall. I. The identification of a mucopeptide in the cell walls of groups $A$ and A variant streptococci. J. exp. Med. 114, 127.

LENNOX, E. S. (1960). Antigenic analysis of cell structure. In The Bacteria, vol. 1, ed. I. C. Gunsalus \& R. Y. Stanier. New York: Academic Press.

Lonkiewicz, Z., Kwas, S. \& Szwed-Nabialek, G. (1963). Antigenic properties of nucleic acids in Rhizobium. Acta Microbiol. Polon. 12, 113.

Niwa, M., Yamadeya, Y. \& Kuwajima, Y. (1964). Leakage of cell components of Bordetella pertussis. J. Bact. 88, 809.

Pappagianis, D., Putman, E. W. \& Kobayashi, G. S. (1961). Polysaccharide of Coccidioides immitis. J. Bact. 82, 714.

Roberts, D. B. \& Patreman, J. A. (1964). Immunological studies of amination deficient strains of Neurospora crassa. J. gen. Microbiol. 34, 295.

Salton, M. J. R. (1957). The action of lytic agents on the surface structures of the bacterial cell. 2nd International Congress on Surface Activity (London), p. 245. London: Butterworths.

Schluchterer, E. \& Stacey, M. (1945). The capsular polysaccharide of Rhizobium radicicolum. J. chem. Soc. p. 776 .

Sevag, M. G., Lackman, D. B. \& Smollens, J. (1935). The isolation of the components of streptococcal nucleoproteins in serologically active form. J. biol. Chem. 124, 425.

Sharpe, M. E., Davison, A. L. \& Baddiley, J. (1964). Teichoic acids and group antigens in Lactobacilli. J. gen. Microbiol. 34, 333.

Vennes, J. W. \& GERhardT, P. (1956). Immunological comparison of isolated surface membranes of Bacillus megaterium. Science, 124, 535.

VinCENT, J. M. (1941). Serological studies of the root-nodule bacteria. I. Strains of Rhizobium meliloti. Proc. Linn. Soc. N.S.W. 66, 145.

VINCENT, J. M. (1962). Influence of calcium and magnesium on the growth of Rhizobium. J. gen. Microbiol. 28, 653.

Vincent, J. M. \& Colburn, J. R. (1961). Cytological abnormalities in Rhizobium trifolii due to deficiency of calcium or magnesium. Aust. J. Sci. 23, 269.

Vincent, J. M. \& Humphrey, B. A. (1963). Partition of divalent cations between bacterial wall and cell contents. Nature, Lond. 199, 149. 